\title{
Desenho: ciência e representação no estudo de abelhas euglossas no campus da universidade estadual de feira de santana
}

\section{Drawing: science and representation in the study of Euglossas bees in the Feira de Santana's Campus University}

Wesley Bento Santana

Graduando em Bacharelado em Ciências Biológicas Universidade Estadual de Feira de Santana, Bahia, Brasil wesleybento15@hotmail.com

\section{Antônio Wilson Silva de Souza}

Doutor em História da Arte Docente do Departamento de Letras e Artes

Universidade Estadual de Feira de Santana, Bahia, Brasil antoniowilsonsilv@gmail.com

\begin{abstract}
RESUMO:
0 presente artigo é uma comunicação do estágio em que se encontram as pesquisas em desenvolvimento no plano de atividades vinculadas ao Projeto de Pesquisa Desenho e Ciência: contribuições, metodologias e técnicas. 0 plano tem como objetivo a representação gráfica de insetos polinizadores presentes no campus da Universidade Estadual de Feira de Santana. Neste texto, se trata do estudo teórico sobre a relação desenho e ciência, bem como se procura transmitir as ideias básicas sobre desenho e, de modo especial, dar informações sobre o exercício do desenho e suas contribuições para o avanço do conhecimento científico. As reflexões sobre desenho derivam da experiência prática do desenho de observação, no manuseio dos materiais e instrumento do desenho e, sobretudo, do estudo das espécies vegetais selecionadas para a representação gráfica.
\end{abstract}

Palavras-chave: desenho; ciência; insetos; polinizadores.

\begin{abstract}
:
The present article is a communication of the stage in that the researches are being developed in the plan of the activities linked to the Research Project Drawing and Science: contributions, methodologies and techniques. The plan aims to graphically represent pollinating insects present at the State University of Feira de Santana campus. This paper deals with the theoretical study on the relationship between drawing and science, as well as seeks to convey the basic ideas about design and, in particular, provide information on the exercise of drawing and their contributions to the advancement of scientific knowledge. The reflections on drawing derived from the practical experience of observational drawing, of handling of drawing materials and instruments, and especially the study of vegetal species selected for graphical representation.
\end{abstract}

Keywords: design; science; insects; pollinators. 


\section{INTRODUÇÃO}

O presente artigo é uma comunicação do atual estágio em que se encontram as reflexões e as atividades de desenho decorrentes da execução do plano de atividades desenvolvidas ao longo do primeiro ano da investigação científica vinculada ao Projeto de Pesquisa intitulado Desenho e Ciência: contribuições, metodologias e técnicas ${ }^{1}$, integrante do Programa de Pós-Graduação em Desenho, Cultura e Interatividade, do Departamento de Letras e Artes da Universidade Estadual de Feira de Santana (UEFS).

Como estudante do curso de graduação em Ciências Biológicas da UEFS, estive sempre atento à presença de animais que povoam o campus, tornando-o um ambiente requerente de uma investigação científica voltada para o registro gráfico e análise de espécimes zoológicos. Dentre os espécimes, nossa atenção se fixou nos polinizadores. 0 motivo de nossa escolha foi a importância ecológica e econômica da polinização para a nossa sociedade.

Sabendo da existência de um projeto de pesquisa, na UEFS, que visava análise e registro visual, pondo acento na vertente científica do desenho, resolvemos criar um plano de atividade que pudesse dar conta desse objetivo. 0 plano de trabalho se encontra em andamento e com previsão de término para o mês de agosto do ano em curso. As atividades desenvolvidas até o presente momento foram: leitura de bibliografia especializada na área de ciências biológicas, com ênfase em zoologia, de modo especial nos insetos polinizadores; e também tivemos acesso a uma bibliografia específica da área de desenho, uma vez que a proposta do trabalho é mostrar como a linguagem do desenho interfere e auxilia a compreensão do conhecimento cientifico.

As ações junto ao projeto de pesquisa em desenvolvimento proporcionam a compreensão sobre a necessidade de um olhar mais aprofundado sobre o desenho. Assim, com base em pesquisa bibliográfica, foi possível verificar que, desde as primeiras manifestações do homem, nas paredes das cavernas, encontram-se registros de desenho de animais que povoavam seu ambiente natural. Esse dado demonstra tanto a capacidade humana de desenhar, quanto a seu interesse pela fauna que, segundo os maiores estudiosos da paleontologia e da História da Arte, se deve a uma necessidade primordial de subsistência, mas também significa um anseio de interferência no desenvolvimento do mundo natural.

\footnotetext{
A princípio, os desenhos feitos pelo homem eram espontâneos e imitativos, de acordo com as ideias que lhe brotavam a cabeça e, num momento posterior, a necessidade de representar ideias mais complexas obrigou-o a usar um conjunto de representações melhor acabadas. O desenho e a pintura atuam como instrumento de investigação para explorar e registrar a natureza, muito utilizado pelos cientistas, inserindo esta união ao campo das ciências (FRANÇA, 2004, p. 1).
}

\footnotetext{
10 projeto em referência foi idealizado e criado pelo Professor Antônio Wilson Silva de Souza e se encontra em execução desde o ano de 2011, na Universidade Estadual de Feira de Santana, contando com apoio financeiro da mesma instituição. 0 objetivo é estudar a relação Desenho-Ciência, investigando, de modo especial, o papel do desenho enquanto meio, isto é, um suporte à comunicação visual de outros campos de saber, e como fim, com metodologia própria, resultando em si numa forma específica de conhecimento. No projeto se almeja também analisar o desenho como instrumento e síntese que dá aporte ao domínio de ciências como: Biologia, Odontologia, Medicina, Enfermagem, Geografia, Matemática, Engenharias, História e Letras.
} 
Por ser um meio de expressão que possibilita a representação da realidade, o desenho foi adentrando o mundo da ciência, o que foi ocorrendo, de modo especial, ao longo da Idade Moderna, quando os métodos de conhecimento científico foram sendo criados, com base em dados racionalistas, motivados, sobretudo, pelo pensamento filosófico europeu. Naquele período, artistas eram também dedicados à investigação científica e para tanto se utilizavam do desenho. Caso emblemático desse vínculo entre desenho e ciência são as produções de Leonardo da Vinci.

Artistas e cientistas recorrem ao desenho no concurso de suas atividades. 0 cientista se utiliza do desenho para realizar experimentos, a fim de obter meios de investigação operativa (BELLUZZO, 1994), como também para confirmar os dados obtidos nas suas experimentações. Em outras palavras, o desenho se apresenta ao cientista como elemento fundamental para o desenvolvimento e comprovação da ciência.

A história do Brasil registra através das expedições científicas, que os desenhos de observação feitos pelos viajantes que as integravam desenvolviam atividades de registro visual gráfico, através dos desenhos de observação. Esse tipo de desenho, em que a escolha da luz e do ângulo era (e é) imprescindível para a representação adequada dos objetos, era a principal ferramenta para a documentação das descobertas científicas.

Importa referir que a técnica mais comumente empregada nos desenhos de observação está pautada na composição de três elementos: o ponto, linha e plano. Os fundamentos do desenho são necessários aos que desejam se expressar graficamente, por essa razão se requer estudo, aplicação e conhecimento basilar para que a linguagem visual TSE estruture e se desenvolva. Assim,

\begin{abstract}
essas noções fundamentais do desenho eram necessárias [também] à representação feita pelos membros das expedições científicas. E continuam sendo prerrogativas para o domínio do desenho, sem as quais o ato de desenhar se tornaria praticamente impossível ou, no mínimo, sem significação expressional adequada à representação da realidade (ALVES, 2007, p. 12).
\end{abstract}

Ato similar ao dos expedicionários, professores e estudantes no mundo contemporâneo continuam a desenvolver atividades de desenho, com intuito além de estético, científico. No caso específico de nosso estudo, a dedicação ao estudo e análise de registro de espécimes animais tem sido um parâmetro na nossa vida acadêmica e investigativa.

A escolha dos insetos se deve, em parte, por que os insetos são o grupo dominante de animais na terra hoje. Eles superam em quantidade todos os outros animais, e estão virtualmente em todos os ambientes. Milhares de espécies diferentes foram descritos e alguns autores acreditam que o número seja bem maior. Muitos insetos são de extremo valor para o homem e a sociedade não existiria sem eles. A polinização permite a produção de muitas colheitas na agricultura, incluindo frutas, trevos, legumes e algodão (BORROR, 1989). A polinização, além de ser essencial para a agricultura ela também atua como importante agente no processo de variabilidade genética para as fanerógamas (plantas com flores).

O estudo sobre insetos é muito útil, não somente para a preservação das espécies, mas também pelo valor sanitário de que se revestem. Nesse sentido, o presente plano de trabalho, cuja proposta é desenhar insetos polinizadores do campus da UEFS encontra justificativa em razão da presença constante desses animais e da sua capacidade de interferir no aspecto paisagístico do ambiente do Campus. 
O modo como surgiu à vida na Terra, apesar de haver várias teorias que tentam explicá-lo, ainda é um mistério. Porém, o curso que a vida tem nos organismos é um fato mais que conhecido. Nós sabemos que todo ser vivo nasce cresce e se reproduz, ou deveria, se as condições ambientais estiverem favoráveis. Mas algumas formas de vida precisam de uma ajuda em alguma dessas etapas, como é o caso de muitas plantas que requerem a mediação de agentes polinizadores para poder se reproduzir.

A polinização é o processo pelo qual o pólen produzido nas anteras (parte masculina da flor) encontra a porção feminina da flor, o gineceu. "0 pólen entra em uma estrutura no carpelo chamada de estigma onde ele é levado até o ovário onde os gametas masculinos e femininos se encontram e formam o embrião" (VALADÃO, 2003, p. 35).

\begin{abstract}
0 pólen é a célula masculina da flor, pois é produzido pelos estames (que junto com o filete e o conectivo formam o androceu), órgãos masculinos. Os órgãos femininos podem estar na mesma ou em outra flor, o conjunto desses órgãos (ovário estilete e estigma) formam o gineceu. Quando o grão de pólen entra em contato com o estigma ele fica aderido por uma substância viscosa, fazendo com que o pólen crie uma estrutura tubular (tubo polínico)que conduz o núcleo do pólen através do estilete até o ovário, onde o gameta masculino encontra 0 gameta feminino (SOUZA, 2002, p. 43).
\end{abstract}

A maioria dos eucariotas se reproduz de forma sexuada, fenômeno que também ocorre nas plantas com flores (fanerógamas) já que a reprodução sexuada é o processo mais eficiente para gerar a variabilidade genética. Nas fanerógamas esse tipo de reprodução se dá através da polinização, mas nem sempre esse mecanismo ocorre facilmente (SOUZA, 2002; VALADÃO, 2003).

Existem dois tipos de polinização: autopolinização/autogamia e polinização cruzada. A autopolinização ocorre em uma mesma flor bissexuada, onde os estames desenvolvidos projetam-se sobre o gineceu, deixando cair os grãos de pólen de suas anteras, os quais se fixam ao estigma. A polinização cruzada é observada em flores unissexuadas de onde ocorre o transplante dos grãos de pólen de uma flor masculina (do androceu) para o estigma da flor feminina, quando a polinização se faz entre flores diferentes é denominada xenogamia (SOUZA, 2002).

Para que ocorra a polinização, a planta necessita de uma aguda de fatores abióticos (forças físicas como o vento e a água) e bióticos [principalmente animais como insetos: abelhas, vespas, borboletas e outros, aves (beija-flores, principalmente) e mamíferos (morcegos, principalmente)] (VALADÃO, 2003). No caso particular desta pesquisa, a área assumida para verificação e análise do fenômeno da polinização é o campus da UEFS que ofereceu a possibilidade de investigação e análise em razão da presença de um grupo relativamente variado de flores, tais como o hibico/Hibiscus rosasinensis, pau-ferro/Caesalpinialeiostachya, Flamboiant/Delonixregiae todas fanerógamas (plantas com flores) que ocorrem no campus da UEFS.

Por mais que os animais, principalmente os insetos, sejam de extrema importância para a polinização existem outras formas de polinização como a anemófila (polinização pelo vento), hidrofilia, ou polinização pela água (SOUZA, 2002; VALADÃO, 2003).

Na polinização Zoófila, que é a principal forma de polinização das fanerógamas atuais, são os animais que ajudam a transportar o pólen de uma planta para outra. Um desse animais é o morcego. A polinização realizada por eles é a Quiropterofilia. Outro tipo de polinização é a Ornitofilia, polinização por aves (VALADÃO, 2003). 
Os insetos, que possuem enorme diversidade de formas e hábitos, são os principais polinizadores. A entomofilia é um tipo de polinização que envolve vários grupos de insetos como abelhas, besouros, borboletas e moscas, constituem a vasta gama de insetos polinizadores (VALADÃO, 2003). As abelhas são os mais eficientes agentes polinizadores, pois apresentam o corpo coberto por cerdas que capturam o pólen além de terem a sua alimentação baseada apenas em pólen e néctar (VALADÃO, 2003). Sendo as abelhas os polinizadores mais eficientes, nós escolhemos esse grupo de insetos, e dele selecionamos as Abelha-de-orquidea (Euglossas).

Antes de começar, de fato, as atividades do projeto, eu fiz uma série de exercícios, recomendados e monitorados pelo professor Antônio Wilson, com a finalidade de facilitar o desenvolvimento do projeto. Dentre eles encontra-se a representação da figura 1 que trata de desenhos de elementos botânicos.

Figuras 1: Representações botânicas. Desenho a grafite sobre papel.
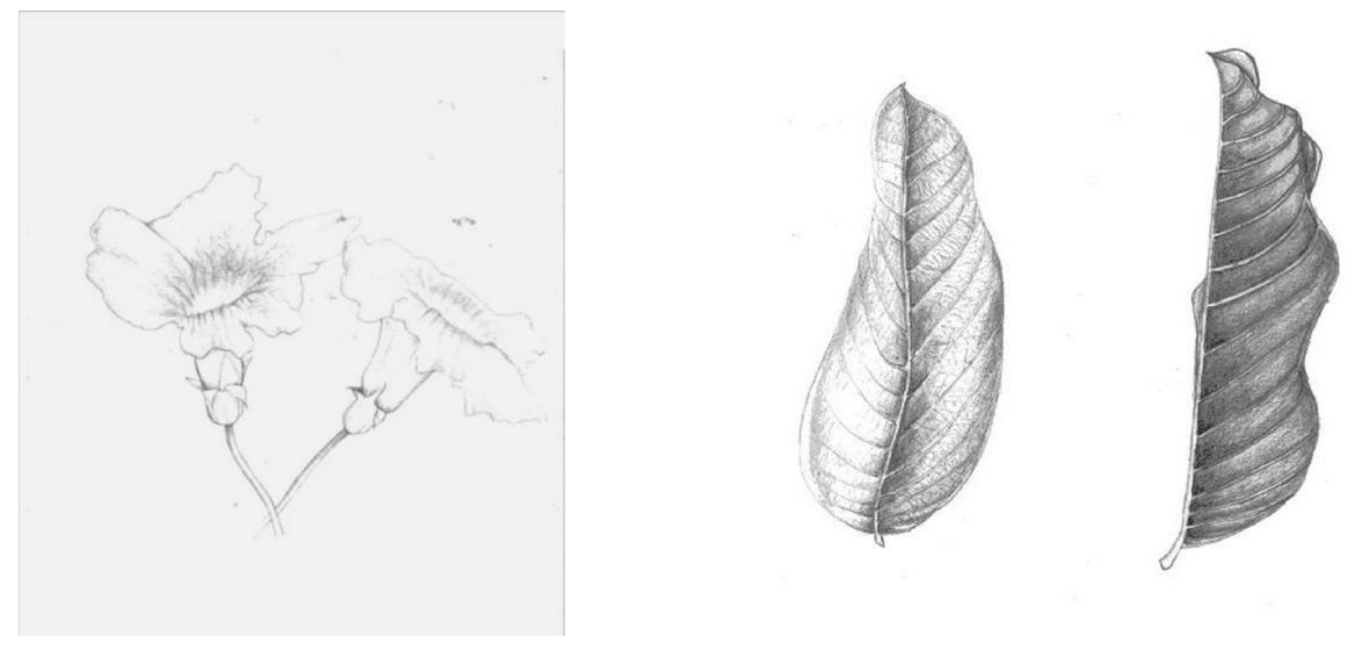

Fonte: Acervo iconográfico do Projeto de Pesquisa Desenho e Ciência: contribuições, metodologias e técnicas (2015). Autor: Wesley Bento Santana.

Feito isso começamos o projeto fazendo uma pesquisa a respeito dos polinizadores, procurando investigar: Quem são? E, o que os caracteriza como um grupo? Feita essa pesquisa, fomos ao Laboratório de Entomologia (LENT) da UEFS onde consultamos a professora Miriam Gimenes, doutora em entomologia. A partir deste contato, decidimos qual grupo de polinizadores dentro dos insetos seria o melhor para ser estudado e representado. A resposta foi o grupo das abelhas, principalmente por sua eficiência como polinizadores e dentro deste grupo as abelhas-de-orquídeas (euglossas). As razões desta escolha estão no fato de que essas abelhas apresentam coloração atípica e por serem pouco conhecidas fora do meio de pesquisadores em entomologia. Outros fatores motivaram a escolha, tais como a quantidade menor de pelos (cerdas), o que facilita a percepção da sua forma, e consequentemente, a sua representação. Com isso nós começamos a fazer o principal produto, concreto, desse projeto; os desenhos da abelha que foram feitos com base nos exemplares e em fotografias feitas dos mesmos, a dedicação à sua representação se encontra registrada nas figuras 2 e 3 (feitas com a técnica de desenho de observação). 
Os desenhos foram feitos em lápis grafite (H, HB, B, 2B e 6B), papel canson e borracha limpa-tipo. Eles representam espécimes que já tinham sido catalogados e integravam o acervo do LENT, do Departamento de Ciências Biológicas da UEFS. Os espécimes foram cedido especialmente pela professora Miriam Gimenes, para estudo analítico e descritivo, a título de exercício de percepção visual e destreza manual, com fins de representação gráfica que se pode ver nas figuras 2 e 3.

Figura 2: Representação da Abelha-de-orquídea (Euglossas). Desenho a grafite sobre papel.

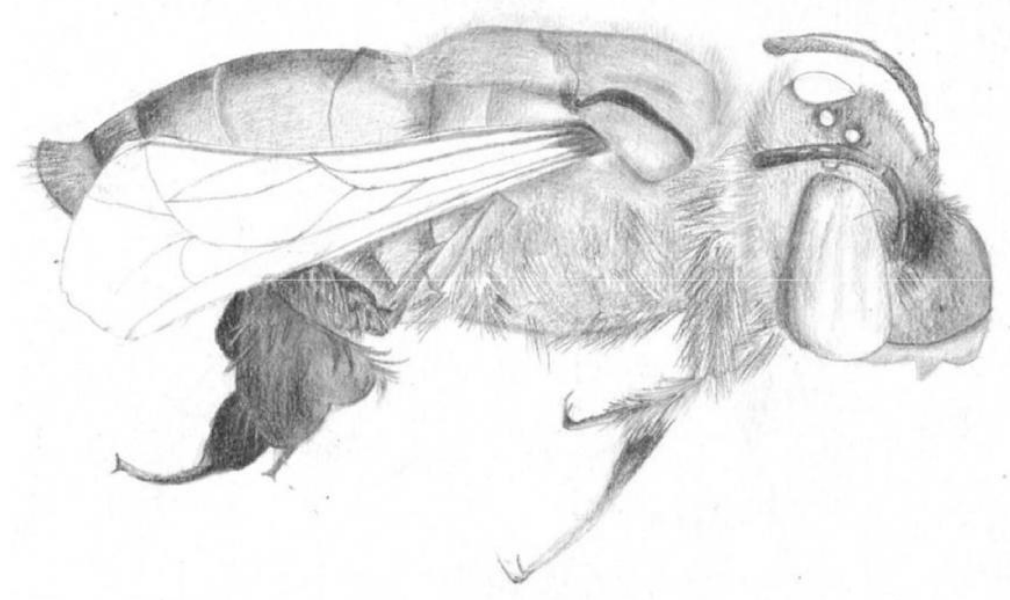

Fonte: Acervo iconográfico do Projeto de Pesquisa Desenho e Ciência: contribuições, metodologias e técnicas (2015). Autor: Wesley Bento Santana.

Os desenhos da figura 1 nos permitiram compreender a proeminência do ato de desenhar e a decorrência lógica do seu exercício. Nesse sentido, concordamos com o que diz Betty Edwards (2002, p. 18):

[...] afirmo que aprender a ver e a desenhar é um modo muito eficiente de educar o sistema visual, assim como aprender a ler e escrever pode educar eficientemente o sistema verbal. Isso não equivale dizer que o sistema visual seja melhor do ponto de vista moral ou de qualquer outro, do que o sistema verbal. Mas os dois sistemas são diferentes. E quando educados como parceiros iguais, um padrão mental melhora o outro, e juntos os dois modos podem liberar a criatividade humana. 
Figura 3: Representação da Abelha-de-orquídea (Euglossas). Desenho a grafite sobre papel.
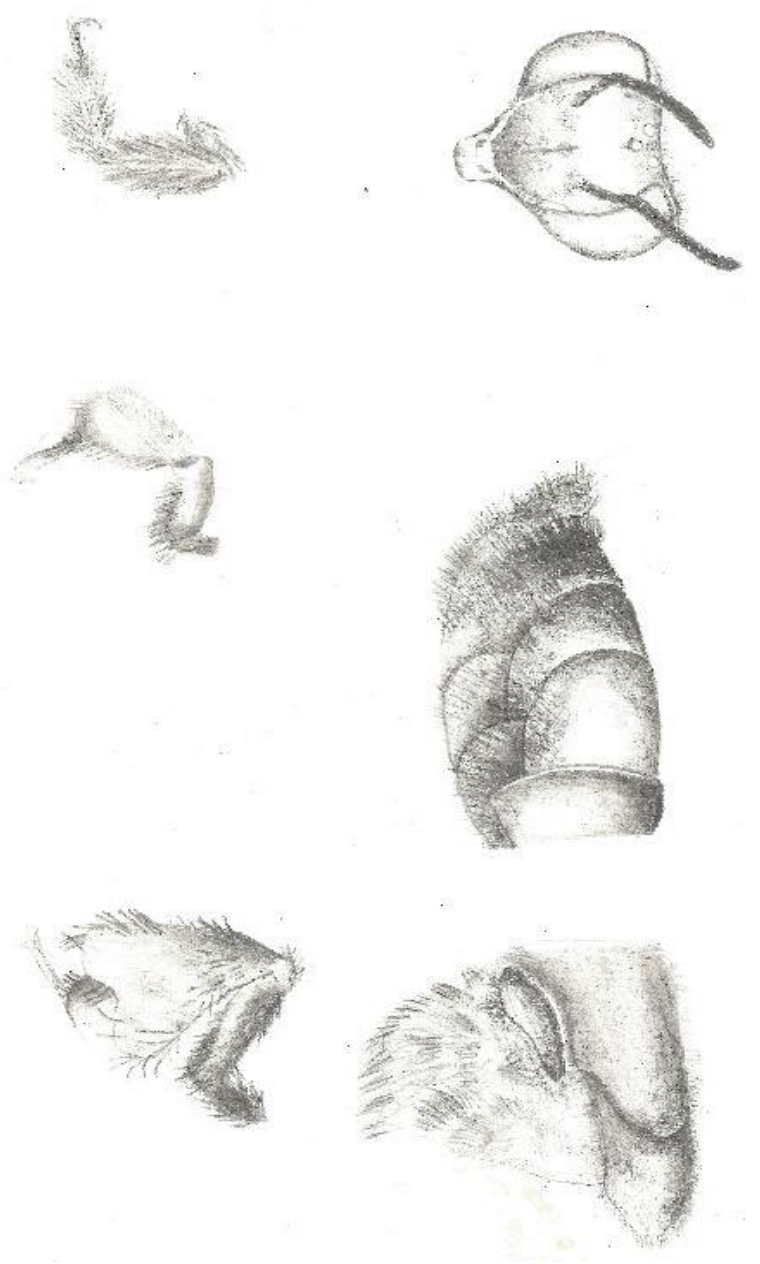

Fonte: Autor: Wesley Bento Santana. Acervo iconográfico do Projeto de Pesquisa Desenho e Ciência: contribuições, metodologias e técnicas (2015)

O pesquisador, portanto, que reconhece a atuação que o exercício do desenho pode exercer sobre o desenvolvimento de sua análise, terá mais chance de alicerçar seu pensamento sobre sólidos fundamentos científicos. Torna-se importante referir que "ao desenhar uma representação de um animal, o seu autor prova já ter adquirido um conceito autônomo que substitui o conjunto dos animais com aquela forma (CÔRTE-REAL, 2001, p. 8).

O desenho da figura 1 mostra a capacidade de refletir, através do desenho sobre a realidade concreta, considerando que o "desenho é uma das capacidades humanas que melhor permite a representação das coisas concretas e abstratas do mundo em que vivemos" (GOMES, 1996, p. 13).

\section{CONSIDERAÇÕES FINAIS}

Apesar das iniciativas acadêmicas pelo uso da linguagem do desenho aliada à ciência, o desenho é ainda hoje utilizado em escala reduzida como vetor do saber científico em algumas instituições de vida acadêmica. Nesse contexto, essa proposta de trabalho se 
justifica também por se apresentar com o objetivo de caracterizar o desenho, não somente como uma produção artística, mas também como um instrumento da ciência, colaborador irrefutável do conhecimento acadêmico.

Após esse ano de pesquisa, pudemos entender que o desenho constitui uma linguagem eficaz e que o exercício desta linguagem permite, através da percepção visual, uma compreensão mais abrangente da realidade. Em se tratando de um projeto de investigação científica, o domínio do desenho foi de suma importância para favorecer o aprofundamento da visualidade, o aguçamento do olhar e a destreza da mão.

As espécies representadas através do desenho se tornaram objeto de análise ainda mais instigadora e estimulante, sobretudo porque o desenho conduz a uma visão multidisciplinar, que se dá no cruzamento da ciência e da arte, tornando a ciência cada vez mais devedora da arte.

\section{REFERÊNCIAS BIBLIOGRÁFICAS}

ALVES, R. M. P. 1 ABCDesenho: caderno de ilustração cientifica. Belo Horizonte: PROEX/UFMG, 2007.

BELluZZO, Ana Maria de Moraes. 0 Brasil dos viajantes. São Paulo: Metalivros, 1994.

BORROR, D. J.; TRIPLEHORN, C. A.; JOHNSON, N. F. An Introduction to the study of Insects. 6 ed. Philadelphia: Saunder College Publishing, 1989.

CÔRTE-REAL, Eduardo. 0 triunfo da virtude: as origens do desenho arquitectónico. Lisboa: Livros Horizonte, 2001.

EDWARDS, Betty. Desenhando com o artista interior. São Paulo: Claridade, 2002.

FRANÇA, I. de C. 0 desenho e as ciências naturais. Feira de Santana: UEFS/ANPHUL, 2004.

GOMES, Luiz Vidal de Negreiros. Desenhismo. 2 ed. Santa Maria-RS: UFSM, 1996.

VALADÃO, V. Mecanismo de polinização. 2003. Monografia apresentada para a conclusão do curso de Biologia - Faculdade de Ciências da Saúde, Centro Universitário de Brasília. Brasília - 1ํㅗ semestre/2003. 35f.

SOUZA, R. Biologia floral do cerrado: polinização e floração. 2002. Monografia apresentada para a conclusão do curso de Biologia - Faculdade de Ciências da Saúde, Centro Universitário de Brasília. Brasília/2002. 43f. 